\title{
An Unknown Physical Constant Missing from Physics
}

\author{
Koshun Suto ${ }^{1}$ \\ ${ }^{1}$ Chudaiji Buddhist Temple, Isesaki, Japan \\ Correspondence: Koshun Suto, Chudaiji Buddhist Temple, 5-24, Oote-Town, Isesaki, 372-0048, Japan. \\ Tel: 81-270-239-980. E-mail: koshun_suto129@mbr.nifty.com
}

Received: April 24, 2014 Accepted: August 21, 2015 Online Published: August 24, 2015

doi:10.5539/apr.v7n5p68 URL: http://dx.doi.org/10.5539/apr.v7n5p68

\begin{abstract}
Planck constant is thought to belong to the universal constants among the fundamental physical constants. However, this paper demonstrates that, just like the fine-structure constant $\alpha$ and the Rydberg constant $R_{\infty}$, Planck constant belongs to the micro material constants. This paper also identifies the existence of a constant smaller than Planck constant. This new constant is a physical quantity with dimensions of angular momentum, just like the Planck constant. Furthermore, this paper points out the possibility that an unknown energy level, which cannot be explained with quantum mechanics, exists in the hydrogen atom.
\end{abstract}

Keywords: Planck constant, Bohr's quantum condition, hydrogen atom, unknown energy level, fine-structure constant, classical electron radius

\section{Introduction}

In 1900, when deriving a equation matching experimental values for black-body radiation, M. Planck proposed the quantum hypothesis that the energy of a harmonic oscillator with frequency $v$ is quantized into integral multiple of $h v$. This was the first time that Planck constant $h$ appeared in physics theory.

Since this time, Planck constant has been thought to be a universal constant among fundamental physical constants.

Fundamental physical constants play an essential part in elementary equations describing natural phenomena and can be broadly divided into universal constants and material constants.

Universal constants include the speed of light in vacuum $c$, Newtonian constant of gravitation $G$, and Planck constant $h$.

Material constants can be divided into micro material constants and macro material constants. Also, micro material constants can be divided into physical quantities and constants.

Physical quantities belonging to the category of micro material constants include the electron rest mass $m_{\mathrm{e}}$, elementary charge $e$, and electron's Compton wavelength $\lambda_{\mathrm{C}}$, and include such constants as the fine-structure constant $\alpha$ and the Rydberg constant $R_{\infty}$.

The Boltzmann constant $k$ and the Avogadro constant $N_{\mathrm{A}}$ are examples of macro material constants.

Incidentally, in deriving the equation for the energy levels of the hydrogen atom, Bohr assumed the following quantum condition including the Planck constant:

$$
p_{n} \cdot 2 \pi r_{n}=2 \pi n \hbar, \quad n=1,2, \cdots .
$$

However, the author has pointed out that Equation (1) is no more than an approximation (Suto, 2014). That is,

$$
p_{n} \cdot 2 \pi r_{n}=2 \pi \hbar \cdot \frac{n}{2}\left[1+\left(1+\alpha^{2} / n^{2}\right)^{1 / 2}\right] \approx 2 \pi n \hbar
$$

Equation (2) is a condition derived from the following equation for the energy levels of the hydrogen atom.

$$
E_{n}=m_{\mathrm{e}} c^{2}\left[\left(\frac{n^{2}}{n^{2}+\alpha^{2}}\right)^{1 / 2}-1\right], \quad n=0,1,2, \cdots .
$$


Equation (3) derived by the author is an equation which increases the precision of the equation derived by Bohr for the energy levels of the hydrogen atom. (However, Equation (3) has not been successfully generalized to an equation including multiple quantum numbers.)

Planck constant does not play an essential role when deriving Equation (3). Thus, the next section of this paper examines whether Planck constant can truly be called a universal constant.

\section{Planck Constant Derived from Fundamental Physical Constant}

The following is Einstein's equation expressing the equality of energy and mass.

$$
E=m c^{2} \text {. }
$$

Here, $m$ is the mass of an object or a particle and $c$ is the speed of light in vacuum.

If $m_{\mathrm{e}}$ is the rest mass of an electron, an electron's mass energy $E_{0}$ can be represented by the following equation.

$$
E_{0}=m_{\mathrm{e}} c^{2}
$$

Meanwhile, Einstein's relational expression regarding light quanta is as follows.

$$
E=h \nu \text {. }
$$

Equation (4) and Equation (6) are traditionally thought to be representative equations of the theories of special relativity and quantum mechanics, the foundations of modern physics, and these two equations have been thought to have similar importance.

If $v_{\mathrm{c}}$ is the frequency of a photon carrying an amount of energy equivalent to $E_{0}$, the following is true.

$$
E_{0}=h v_{\mathrm{C}} \text {. }
$$

Next, let us calculate the wavelength of a photon with frequency $v_{\mathrm{c}}$.

Combining equals from Equation (5) and Equation (7), we obtain:

$$
m_{\mathrm{e}} c^{2}=h v_{\mathrm{C}}
$$

Equation (5) expresses the energy possessed by an electron with rest mass $m_{\mathrm{e}}$. Also, Equation (7) indicates the relationship between photon's frequency and energy.

Fundamentally these two types of energy have different characteristics, but from a quantitative perspective, it is possible to combine them as equals.

Thus, the photon's frequency $v_{\mathrm{c}}$ is expressed as follows.

$$
v_{\mathrm{C}}=\frac{m_{\mathrm{e}} c^{2}}{h} \text {. }
$$

Next, the photon's wavelength $\lambda$ becomes:

$$
\lambda=\frac{c}{v_{\mathrm{C}}}=\frac{h}{m_{\mathrm{e}} c}=\lambda_{\mathrm{C}} .
$$

Thus, Equation (5) can be transformed as follows.

$$
m_{\mathrm{e}} c^{2}=m_{\mathrm{e}} c \lambda_{\mathrm{C}} \nu_{\mathrm{C}}
$$

In Equation (11), $\lambda_{\mathrm{C}}$ is the wavelength of a photon, not an electron. However, because the right sides of Equation (11) and Equation (8) match, the following relationship holds true in the case of a photon as well.

$$
m_{\mathrm{e}} c \lambda_{\mathrm{C}}=h
$$

Now, let us consider the case where the photon energy is not $m_{\mathrm{e}} c^{2}$.

If the rest mass of the electron decreases by just a $m_{\mathrm{e}}$ then the energy $\mathrm{a} E_{0}$ of the photon emitted from that electron is given by the following equation.

$$
\mathrm{a} E_{0}=\mathrm{a} m_{\mathrm{e}} c^{2}, \quad(\text { when } 0<\mathrm{a}<1) .
$$

This equation can also be written as follows. 


$$
E=\mathrm{a} E_{0}=\mathrm{a} m_{\mathrm{e}} c \lambda_{\mathrm{C}} \nu_{\mathrm{C}}=m_{\mathrm{e}} c \lambda_{\mathrm{C}} \cdot \mathrm{a} v_{\mathrm{C}}=h v .
$$

Finally, it was possible to confirm that Equation (6) holds in general.

The currently known values for $m_{\mathrm{e}}$ or $\lambda_{\mathrm{C}}$ were not determined through experimentation. $m_{\mathrm{e}}$ was determined through precise calculations from Rydberg constant formulas, and $\lambda_{\mathrm{C}}$ was obtained by substituting $m_{\mathrm{e}}$ in the formula $\lambda_{\mathrm{C}}=h / m_{\mathrm{e}} c$. Many fundamental physical constants are being adjusted, based on measured data from theoretical equations or experiments designed to represent the fundamental laws of physics, to avoid conflicts from arising between these constants.

Because the equation for determining an electron's Compton wavelength is $\lambda_{\mathrm{C}}=h / m_{\mathrm{e}} c$, naturally the modified version of this Equation (12) is true.

According to traditional classical quantum mechanics, Planck constant exists a priori as a universal constant, and thus it is thought that the energy of a photon can be determined if its frequency is known, and the wavelength of a quantum can be determined if its momentum is known $(E=h v$ and $\lambda=h / p)$.

In this paper, however, a logical case is made that, since the product of the momentum and wavelength of any photon can be expressed by the constant $m_{\mathrm{e}} c \lambda_{\mathrm{C}}$, Planck constant only comes into existence when $m_{\mathrm{e}} c \lambda_{\mathrm{C}}$ is replaced with $h$.

In other words, Equation (12) can be interpreted to mean not that "the value of $m_{\mathrm{e}} c \lambda_{\mathrm{C}}$ and $h$ match" but instead to mean " $m_{\mathrm{e}} c \lambda_{\mathrm{C}}$ is $h$."

In this paper, we show that Planck constant is not a universal constant but is instead just a micro material constants on a par with the fine-structure constant $\alpha$ and the Rydberg constant $R_{\infty}$.

\section{An Unknown Physical Constant Missing from Physics}

In the classical quantum theory of Bohr, the energy levels of the hydrogen atom can be expressed with the following equation.

$$
E_{n}=-\frac{1}{2}\left(\frac{1}{4 \pi \varepsilon_{0}}\right)^{2} \frac{m_{\mathrm{e}} e^{4}}{\hbar^{2}} \cdot \frac{1}{n^{2}}, \quad n=1,2, \cdots .
$$

When Bohr derived this equation, he assumed the quantum condition in Equation (1).

From Equation (1), the product $p_{1} r_{1}$ of the minimum value of the momentum $p_{1}$ and the minimum value of the radius $r_{1}$ is as follows.

$$
p_{1} r_{1}=\hbar \text {. }
$$

Incidentally, the author has derived a relation between energy and momentum, applicable to the electron in the hydrogen atom, from the perspective of classical theory (Suto, 2011). That is,

$$
E_{\mathrm{re}, n}^{2}+\boldsymbol{p}_{n}^{2} c^{2}=\left(m_{\mathrm{e}} c^{2}\right)^{2}, \quad n=1,2, \cdots
$$

Also, $E_{\mathrm{re}, n}$ has been defined as follows.

$$
E_{\mathrm{re}, n}=m_{\mathrm{e}} c^{2}+E_{n} .
$$

Here, $E_{\mathrm{re}, n}$ is the relativistic energy of the electron, and the electron's energy is described on an absolute scale.

Now, the following equation can be derived by comparing $E_{\mathrm{re}, n}$ defined with Equation (18) and Equation (3).

$$
E_{\mathrm{re}, n}=m_{\mathrm{e}} c^{2}\left(\frac{n^{2}}{n^{2}+\alpha^{2}}\right)^{1 / 2}, \quad \alpha=\frac{1}{4 \pi \varepsilon_{0}} \frac{e^{2}}{\hbar c} .
$$

Next, if the right side of Equation (19) is substituted for Equation (17), then the following equation can be derived.

$$
p_{n}=m_{\mathrm{e}} c\left(\frac{\alpha^{2}}{n^{2}+\alpha^{2}}\right)^{1 / 2} .
$$


If 0 is substituted here for $n$ in Equation (20),

$$
p_{0}=m_{\mathrm{e}} c
$$

$p_{0}$ is obtained, and thus in this case we will find $r_{0}$.

First, the energy of the hydrogen atom is given by the following equation.

$$
E_{n}=-\frac{1}{2} \frac{1}{4 \pi \varepsilon_{0}} \frac{e^{2}}{r_{n}}
$$

Due to this equation and Equation (18), the relativistic energy $E_{\mathrm{re}, n}$ becomes as follows.

$$
E_{\mathrm{re}, n}=m_{\mathrm{e}} c^{2}-\frac{1}{2} \frac{1}{4 \pi \varepsilon_{0}} \frac{e^{2}}{r_{n}} .
$$

Here, the right sides of Equation (19) and Equation (23) are connected with an equals sign. That is,

$$
m_{\mathrm{e}} c^{2}\left(\frac{n^{2}}{n^{2}+\alpha^{2}}\right)^{1 / 2}=m_{\mathrm{e}} c^{2}-\frac{1}{2} \frac{1}{4 \pi \varepsilon_{0}} \frac{e^{2}}{r_{n}} .
$$

If $r_{n}$ is found from that,

$$
r_{n}=\frac{1}{2} \frac{e^{2}}{4 \pi \varepsilon_{0} m_{\mathrm{e}} c^{2}}\left[1-\frac{1}{\left(1+\alpha^{2} / n^{2}\right)^{1 / 2}}\right]^{-1}=\frac{r_{\mathrm{e}}}{2} \frac{\left(n^{2}+\alpha^{2}\right)^{1 / 2}}{\left(n^{2}+\alpha^{2}\right)^{1 / 2}-n} .
$$

Here, $r_{\mathrm{e}}$ is the classical electron radius.

Next, if 0 is substituted for $n$ in Equation (25),

$$
r_{0}=\frac{1}{2} \frac{1}{4 \pi \varepsilon_{0}} \frac{e^{2}}{m_{\mathrm{e}} c^{2}}=\frac{r_{\mathrm{e}}}{2} .
$$

Finally, $p_{0} r_{0}$ is as follows due to Equation (21) and Equation (26) (see Appendix).

$$
p_{0} r_{0}=m_{\mathrm{e}} c \cdot \frac{r_{\mathrm{e}}}{2}=\frac{1}{2} \frac{1}{4 \pi \varepsilon_{0}} \frac{e^{2}}{c} .
$$

This $p_{0} r_{0}$ value is not an approximate value. However, as is clear from Equation (2), $p_{1} r_{1}$ in Equation (16) is an approximate value. Therefore, this paper concludes that the value of this $p_{0} r_{0}$ is a physical quantity more basic than $p_{1} r_{1}$ in Equation (16).

In this paper, this physical quantity is tentatively called $\hbar_{\mathrm{s}}$ and positioned as a constant on a par with Planck constant. That is,

$$
\hbar_{\mathrm{s}}=\frac{1}{2} \frac{1}{4 \pi \varepsilon_{0}} \frac{e^{2}}{c} .
$$

A small $\mathrm{s}$ is used as the subscript s of $\hbar_{\mathrm{s}}$. This signifies that $\hbar_{\mathrm{s}}$ is a smaller quantity than $\hbar$. The relationships between $\hbar_{\mathrm{s}}$ and $\hbar$, and between $h_{\mathrm{s}}$ and $h$ are as follows.

$$
\begin{aligned}
& \hbar_{\mathrm{s}}=\frac{1}{2} \alpha \hbar . \\
& h_{\mathrm{s}}=\frac{1}{2} \alpha h .
\end{aligned}
$$

If, in Equation (29.1), $\hbar$ and $\alpha$ are micro material constants, then it is natural to regard $\hbar_{\mathrm{s}}$ in the same way.

If the relationship in Equation (29.2) is used here, then Equation (6) can be written as follows.

$$
E=\frac{2}{\alpha} h_{\mathrm{s}} v .
$$


This paper predicts that Equation (30) will be an important equation just like Equation (6).

Normally, the energy of a photon is thought to be proportional to the photon's frequency. However, Equation (6) does nothing more than signify that the photon's energy $E$ is expressed by the product of $h$ and $v$. (Since $h$ has dimensions, it cannot be said that $h$ is a constant of proportionality). In Equation (30), in contrast, 2/ $\alpha$ becomes the constant of proportionality, and thus it is possible to interpret the photon energy as varying in proportion to $h_{\mathrm{s}} v$. Also, $h_{\mathrm{s}}$ is a constant, and thus the fact that energy is proportional to $h_{\mathrm{s}} v$ has the same meaning as energy being proportional to $v$. That is,

$$
E=\frac{2}{\alpha} \cdot h_{\mathrm{s}} v=\frac{2 h_{\mathrm{s}}}{\alpha} \cdot v=h v .
$$

So, is there experimental data supporting the inclusion of $\hbar_{\mathrm{s}}$ among physical constants?

To solve this problem, this paper assumes, on a trial basis, that there is an unknown energy level in the hydrogen atom.

Then an equation for the unknown is derived by using a condition similar to the Bohr's quantum condition. Then the values obtained from the equation are compared with experimental data to determine whether or not they match. If the theory of quantum mechanics is complete, there should be no match between experimental data and the value predicted by the equation for the unknown.

However, if there is a match between the theoretical value and observed data, this can be regarded as powerful evidence supporting inclusion of $\hbar_{\mathrm{s}}$ among the physical constants.

\section{Derivation of Equation for Unknown Energy Level}

If it is assumed that an unknown energy level exists in the hydrogen atom, what is the best method of deriving an equation for it? The following confirms that procedure.

1. It is difficult to derive an unknown equation, and thus we begin by predicting an approximation of the unknown equation, while referring to Bohr's quantum condition. At that time, it is assumed that the following relation holds, which is similar to Bohr's quantum condition.

$$
p_{n^{\prime}} \cdot 2 \pi r_{n^{\prime}}=2 \pi n^{\prime} \hbar_{\mathrm{s}}=2 \pi n^{\prime} \cdot \frac{\alpha}{2} \hbar, \quad n^{\prime}=1,2, \cdots .
$$

2. Taking into account the fact that the approximation of Equation (3) is Bohr's equation (15), in this case the original equation is derived by proceeding backwards from the derived approximation.

Let us suppose that an atomic nucleus is at rest because it is heavy, and consider the situation where an electron (electric charge $-e$, mass $m_{\mathrm{e}}$ ) is orbiting at speed $v$ along an orbit (radius $r$ ) with the atomic nucleus as its center. An equation describing this motion is as follows:

$$
\frac{m_{\mathrm{e}} v^{2}}{r}=\frac{1}{4 \pi \varepsilon_{0}} \frac{e^{2}}{r^{2}}
$$

The following equation is derived by multiplying both sides of the above equation by $r^{3}$ and using Equation (32).

$$
r_{n^{\prime}}=4 \pi \varepsilon_{0} \frac{\hbar^{2}}{m_{\mathrm{e}} e^{2}}\left(\frac{\alpha}{2}\right)^{2} n^{\prime 2}, \quad n^{\prime}=1,2, \cdots
$$

To agree with $n^{\prime}$ on the light side, $n^{\prime}$ is added to $r$ on the left side.

Next, the following equation is derived when this $r_{n^{\prime}}$ is substituted into Equation (22) and the subscript $n^{\prime}$ is attached to $E$.

$$
E_{n^{\prime}}^{\prime}=-\frac{1}{2}\left(\frac{1}{4 \pi \varepsilon_{0}}\right)^{2} \frac{m_{\mathrm{e}} e^{4}}{\hbar^{2}}\left(\frac{2}{\alpha}\right)^{2} \cdot \frac{1}{n^{\prime 2}}, \quad n^{\prime}=1,2, \cdots .
$$

Here, energy is taken to be $E^{\prime}$ in order to distinguish from existing equations of quantum mechanics.

Incidentally, Bohr's equation (15) can be written as follows. 


$$
E_{n}=-\frac{1}{2}\left(\frac{1}{4 \pi \varepsilon_{0}}\right)^{2} \frac{m_{\mathrm{e}} e^{4}}{\hbar^{2}} \cdot \frac{1}{n^{2}}=-\frac{1}{2} \alpha^{2} m_{\mathrm{e}} c^{2} \cdot \frac{1}{n^{2}}, \quad n=1,2, \cdots .
$$

In contrast, Equation (35) can be written as follows.

$$
E_{n^{\prime}}^{\prime}=-\frac{1}{2} \alpha^{2} m_{\mathrm{e}} c^{2}\left(\frac{2}{\alpha}\right)^{2} \cdot \frac{1}{n^{\prime 2}}, \quad n^{\prime}=1,2, \cdots .
$$

Next, we confirm that Equation (15) is an approximation for Equation (3). First, Equation (3) can be written as follows.

$$
\begin{gathered}
E_{n}=m_{\mathrm{e}} c^{2}\left[\left(\frac{n^{2}}{n^{2}+\alpha^{2}}\right)^{1 / 2}-1\right] \\
=m_{\mathrm{e}} c^{2}\left[\frac{\left(1-\alpha^{2} / n^{2}\right)^{1 / 2}}{\left(1+\alpha^{2} / n^{2}\right)^{1 / 2}\left(1-\alpha^{2} / n^{2}\right)^{1 / 2}}-1\right] \\
=m_{\mathrm{e}} c^{2}\left[\left(1-\frac{\alpha^{4}}{n^{4}}\right)^{-1 / 2}\left(1-\frac{\alpha^{2}}{n^{2}}\right)^{1 / 2}-1\right], \quad n=0,1,2, \cdots .
\end{gathered}
$$

Here, $\alpha^{4} / n^{4} \approx 0$ and therefore,

$$
\left(1-\frac{\alpha^{4}}{n^{4}}\right)^{-1 / 2} \approx 1
$$

That means Equation (38.3) can be written as follows.

$$
E_{n} \approx m_{\mathrm{e}} c^{2}\left[\left(1-\frac{\alpha^{2}}{n^{2}}\right)^{1 / 2}-1\right], \quad n=0,1,2, \cdots .
$$

The Taylor expansion of this formula is as follows.

$$
E_{n} \approx m_{\mathrm{e}} c^{2}\left[\left(1-\frac{\alpha^{2}}{n^{2}}\right)^{1 / 2}-1\right]=m_{\mathrm{e}} c^{2}\left(-\frac{\alpha^{2}}{2 n^{2}}-\frac{\alpha^{4}}{8 n^{4}}+\cdots\right) .
$$

The second and subsequent terms in the parentheses can be regarded as zero, and thus if only the first term is used, the result is as follows.

$$
E_{n} \approx-\frac{\alpha^{2}}{2} m_{\mathrm{e}} c^{2} \cdot \frac{1}{n^{2}}, \quad n=1,2, \cdots
$$

The above demonstrates that Bohr's equation (15) is an approximation of Equation (3).

Now, this time we will apply the logic used thus far to Equation (37). Equation (36) used only the first term in parentheses in Equation (41). Therefore, referring to Equation (41), we can predict that the Taylor expansion of the equation to be found will be as follows.

$$
E_{n^{\prime}}^{\prime} \approx m_{\mathrm{e}} c^{2}\left[\left\{1-\left(\frac{2}{\alpha}\right)^{2} \frac{\alpha^{2}}{n^{\prime 2}}\right\}^{1 / 2}-1\right] \approx m_{\mathrm{e}} c^{2}\left[-\frac{1}{2}\left(\frac{2}{\alpha}\right)^{2} \frac{\alpha^{2}}{n^{\prime 2}}-\frac{1}{8}\left(\frac{2}{\alpha}\right)^{4} \frac{\alpha^{4}}{n^{\prime 4}}+\cdots\right] .
$$

If the relationship between Equation (41) and Equation (38.3) is taken into account here, then it can be predicted that Equation (43) is an approximation of the following equation. 


$$
E_{n^{\prime}}^{\prime}=m_{\mathrm{e}} c^{2}\left[\left(1-\frac{2^{4}}{n^{\prime 4}}\right)^{-1 / 2}\left(1-\frac{2^{2}}{n^{\prime 2}}\right)^{1 / 2}-1\right] .
$$

If the fact that Equation (38.3) is derived from Equation (38.2) is taken into consideration, Equation (44) can be written as follows.

$$
E_{n^{\prime}}^{\prime}=m_{\mathrm{e}} c^{2}\left[\frac{\left(1-2^{2} / n^{\prime 2}\right)^{1 / 2}}{\left(1+2^{2} / n^{\prime 2}\right)^{1 / 2}\left(1-2^{2} / n^{2}\right)^{1 / 2}}-1\right] .
$$

Rearranging this equation, the following equation can be derived.

$$
E_{n^{\prime}}^{\prime}=m_{\mathrm{e}} c^{2}\left[\left(\frac{n^{\prime 2}}{n^{\prime 2}+4}\right)^{1 / 2}-1\right], \quad n^{\prime}=0,1,2, \cdots .
$$

This is the equation for the unknown energy level of the hydrogen atom which this paper is proposing as a springboard for discussion.

\section{Comparison of Theoretical and Measured Values}

In this section, we search other papers for experimental data matching theoretical data obtained from Equation (46).

However, comparison of theoretical values and experimental data is not done in order to prove the correctness of Equation (46). This comparison is carried out to obtain evidence supporting recognition of $\hbar_{\mathrm{s}}$ as a physical constant. Equation (46) does not necessarily have to be correct in order to recognize $\hbar_{\mathrm{s}}$ as a physical constant. Even if it is tentatively assumed that there is no experimental data matching the theoretical data, that is not a reason to reject the considerations in section 3.

Also, conversely, even if theoretical values and experimental data match, that is not conclusive evidence that the experimental data is a transition energy between the energy levels at issue here.

For the above reasons, this paper uses the simple method of an Internet search to search for experimental data. In addition, the comparison of theoretical values and experimental data is performed by limiting to the following range.

Task 1. First, the energy level $E_{n^{\prime}}^{\prime}$ in Equation (46) is calculated from $n^{\prime}=0$ to 600 . Then it is checked whether or not that theoretical value is actually observed. Searching is performed with the terms: "hydrogen atom," "energy level," and "the theoretical value to be checked."

Task 2. It is confirmed whether or not a value is actually observed which matches the transition energy $E$ between different energy levels $E_{n^{\prime}}^{\prime}$ and $E_{m^{\prime}}^{\prime}$. Here, $E_{n^{\prime}, m^{\prime}}=E_{n^{\prime}}^{\prime}-E_{m^{\prime}}^{\prime},\left(n^{\prime} \neq m^{\prime}, n^{\prime}>m^{\prime}\right)$.

This task is performed in the following three energy ranges. Searching is performed with the terms: "hydrogen atom," "transition energy," and "the theoretical value to be checked."

1) Energy range from $E_{0}^{\prime}$ to $E_{10}^{\prime}$.

2) Energy range from $E_{270}^{\prime}$ to $E_{279}^{\prime}$. However, this includes $E_{1}$ found from Equation (3).

3) Energy range from $E_{544}^{\prime}$ to $E_{553}^{\prime}$. However, this includes $E_{2}$ found from Equation (3).

First, for Task 1, it was confirmed that there is experimental data numerically matching the energy level from $E_{0}^{\prime}$ to $E_{600}^{\prime}$. (However, that measurement value does not prove the existence of the pertinent energy level.)

Next, Table 1-3 summarizes the results of Task 2 (See Table 1, 2, 3).

Based on the above comparison, this paper has determined that there exists experimental data numerically matching theoretical values. (However, even this case is not conclusive evidence that the measured values are the pertinent transition energies.)

However, no evidence was obtained that Equation (46) is a mistake. Thus, in this paper it was determined that there is no problem with recognizing $\hbar_{\mathrm{s}}$ as a physical constant.

The discussion in this paper does not reach a conclusion regarding whether Equation (46) is correct or not. However, this paper predicts that in the hydrogen atom there is an energy level lower than the energy levels predicted by quantum mechanics. 
Table 1. Transition energy confirmed in the energy range from $E_{0}^{\prime}$ to $E_{10}^{\prime}$. The measured values in this table almost match the theoretical values. This table was originally longer in the horizontal direction. However, for reasons of page space, the original table was divided here by cutting it vertically in the center of the left-right direction. Then the right half of the table was placed under the left half. The dotted line on the top right edge and the dotted line at the low left edge overlap in the original table. Also, in the paired numerical values in the table, the top figure is the theoretical value. The bottom figure is a value obtained by a search, and is a measurement value close to the theoretical value (The same remarks apply to Table 2 and 3 below).

\begin{tabular}{|c|c|c|c|c|c|}
\hline & $E_{0}^{\prime}$ & $E_{1}^{\prime}$ & $E_{2}^{\prime}$ & $E_{3}^{\prime}$ & $E_{4}^{\prime}$ \\
\hline $\begin{aligned} E_{0}^{\prime}= & -0.5110 \mathrm{MeV} \\
& -0.511 \mathrm{MeV}\end{aligned}$ & 0 & - & - & - & - \\
\hline $\begin{aligned} E_{1}^{\prime}= & -0.2825 \mathrm{MeV} \\
& -0.282 \mathrm{MeV}\end{aligned}$ & $\begin{array}{l}0.2285 \mathrm{MeV} \\
0.229 \mathrm{MeV}\end{array}$ & 0 & - & - & - \\
\hline $\begin{aligned} E_{2}^{\prime}= & -0.1497 \mathrm{MeV} \\
& -0.150 \mathrm{MeV}\end{aligned}$ & $\begin{array}{l}0.3613 \mathrm{MeV} \\
0.361 \mathrm{MeV}\end{array}$ & $\begin{array}{l}0.1328 \mathrm{MeV} \\
0.133 \mathrm{MeV}\end{array}$ & 0 & - & - \\
\hline $\begin{aligned} E_{3}^{\prime}= & -85.82 \mathrm{keV} \\
& -85.8 \mathrm{keV}\end{aligned}$ & $\begin{array}{l}0.4252 \mathrm{MeV} \\
0.425 \mathrm{MeV}\end{array}$ & $\begin{array}{l}0.1967 \mathrm{MeV} \\
0.197 \mathrm{MeV}\end{array}$ & $\begin{array}{l}63.85 \mathrm{keV} \\
63.8 \mathrm{keV}\end{array}$ & 0 & - \\
\hline $\begin{aligned} E_{4}^{\prime}= & -53.95 \mathrm{keV} \\
& -53.9 \mathrm{keV}\end{aligned}$ & $\begin{array}{l}0.4571 \mathrm{MeV} \\
0.475 \mathrm{MeV}\end{array}$ & $\begin{array}{l}0.2285 \mathrm{MeV} \\
0.229 \mathrm{MeV}\end{array}$ & $\begin{array}{l}95.72 \mathrm{keV} \\
95.7 \mathrm{keV}\end{array}$ & $\begin{array}{l}31.87 \mathrm{keV} \\
31.9 \mathrm{keV}\end{array}$ & 0 \\
\hline$E_{5}^{\prime}=-36.55 \mathrm{keV}$ & $0.4745 \mathrm{MeV}$ & $0.2459 \mathrm{MeV}$ & $0.1131 \mathrm{MeV}$ & $49.27 \mathrm{keV}$ & $17.40 \mathrm{keV}$ \\
\hline$-36.5 \mathrm{keV}$ & $0.474 \mathrm{MeV}$ & $0.246 \mathrm{MeV}$ & $0.113 \mathrm{MeV}$ & $49.3 \mathrm{keV}$ & $17.4 \mathrm{keV}$ \\
\hline$E_{6}^{\prime}=-26.22 \mathrm{keV}$ & $0.4848 \mathrm{MeV}$ & $0.2563 \mathrm{MeV}$ & $0.1234 \mathrm{MeV}$ & $59.60 \mathrm{keV}$ & $27.72 \mathrm{keV}$ \\
\hline$-26.2 \mathrm{keV}$ & $0.485 \mathrm{MeV}$ & $0.256 \mathrm{MeV}$ & $0.123 \mathrm{MeV}$ & $59.6 \mathrm{keV}$ & $27.72 \mathrm{keV}$ \\
\hline$E_{7}^{\prime}=-19.66 \mathrm{keV}$ & $0.4913 \mathrm{MeV}$ & $0.2628 \mathrm{MeV}$ & $0.1300 \mathrm{MeV}$ & $66.16 \mathrm{keV}$ & $34.29 \mathrm{keV}$ \\
\hline$-19.7 \mathrm{keV}$ & $0.491 \mathrm{MeV}$ & $0.263 \mathrm{MeV}$ & $0.130 \mathrm{MeV}$ & $66.2 \mathrm{keV}$ & $34.3 \mathrm{keV}$ \\
\hline$E_{8}^{\prime}=-15.26 \mathrm{keV}$ & $0.4957 \mathrm{MeV}$ & $0.2672 \mathrm{MeV}$ & $0.1344 \mathrm{MeV}$ & $70.57 \mathrm{keV}$ & $38.69 \mathrm{keV}$ \\
\hline$-15.3 \mathrm{keV}$ & $0.496 \mathrm{MeV}$ & $0.267 \mathrm{MeV}$ & $0.134 \mathrm{MeV}$ & $70.6 \mathrm{keV}$ & $38.7 \mathrm{keV}$ \\
\hline$E_{9}^{\prime}=-12.17 \mathrm{keV}$ & $0.4988 \mathrm{MeV}$ & $0.2703 \mathrm{MeV}$ & $0.1375 \mathrm{MeV}$ & $73.65 \mathrm{keV}$ & $41.78 \mathrm{keV}$ \\
\hline$-12.2 \mathrm{keV}$ & $0.499 \mathrm{MeV}$ & $0.270 \mathrm{MeV}$ & $0.1375 \mathrm{MeV}$ & $73.7 \mathrm{keV}$ & $41.8 \mathrm{keV}$ \\
\hline$E_{10}^{\prime}=-9.923 \mathrm{keV}$ & $0.5011 \mathrm{MeV}$ & $0.2726 \mathrm{MeV}$ & $0.1397 \mathrm{MeV}$ & $75.90 \mathrm{keV}$ & $44.02 \mathrm{keV}$ \\
\hline$-9.92 \mathrm{keV}$ & $0.501 \mathrm{MeV}$ & $0.273 \mathrm{MeV}$ & $0.140 \mathrm{MeV}$ & $75.9 \mathrm{keV}$ & $44.0 \mathrm{keV}$ \\
\hline$E_{5}^{\prime}$ & $E_{6}^{\prime}$ & $E_{7}^{\prime}$ & $E_{8}^{\prime}$ & $E_{9}^{\prime}$ & $E_{10}^{\prime}$ \\
\hline 0 & - & - & - & - & - \\
\hline $\begin{aligned} E_{6,5}= & 10.33 \mathrm{keV} \\
& 10.33 \mathrm{k} \mathrm{eV}\end{aligned}$ & 0 & - & - & - & - \\
\hline $\begin{aligned} E_{7,5}= & 16.89 \mathrm{keV} \\
& 16.89 \mathrm{keV}\end{aligned}$ & $\begin{array}{l}6.562 \mathrm{keV} \\
6.56 \mathrm{keV}\end{array}$ & 0 & - & - & - \\
\hline $\begin{array}{r}E_{8,5}=21.29 \mathrm{keV} \\
21.29 \mathrm{keV}\end{array}$ & $\begin{array}{l}10.97 \mathrm{keV} \\
11.0 \mathrm{keV}\end{array}$ & $\begin{array}{l}4.404 \mathrm{keV} \\
4.40 \mathrm{keV}\end{array}$ & 0 & - & - \\
\hline $\begin{array}{r}E_{9,5}=24.38 \mathrm{keV} \\
24.38 \mathrm{keV}\end{array}$ & $\begin{array}{l}14.05 \mathrm{keV} \\
14.1 \mathrm{keV}\end{array}$ & $\begin{array}{l}7.493 \mathrm{keV} \\
7.5 \mathrm{keV}\end{array}$ & $\begin{array}{l}3.089 \mathrm{keV} \\
3.08 \mathrm{keV}\end{array}$ & 0 & - \\
\hline $\begin{aligned} E_{10,5}= & 26.63 \mathrm{keV} \\
& 26.63 \mathrm{keV}\end{aligned}$ & $\begin{array}{l}16.30 \mathrm{keV} \\
16.3 \mathrm{keV}\end{array}$ & $\begin{array}{l}9.738 \mathrm{keV} \\
9.74 \mathrm{keV}\end{array}$ & $\begin{array}{l}5.334 \mathrm{keV} \\
5.33 \mathrm{keV}\end{array}$ & $\begin{array}{l}2.245 \mathrm{keV} \\
2.25 \mathrm{keV}\end{array}$ & 0 \\
\hline
\end{tabular}


Table 2. Transition energy confirmed in the energy range from $E_{270}^{\prime}$ to $E_{279}^{\prime}$. The measured values in this table almost match the theoretical values

\begin{tabular}{|c|c|c|c|c|c|}
\hline & $E_{270}^{\prime}$ & $E_{271}^{\prime}$ & $E_{272}^{\prime}$ & $E_{273}^{\prime}$ & $E_{274}^{\prime}$ \\
\hline $\begin{aligned} E_{270}^{\prime}= & -14.019 \mathrm{eV} \\
& -14.02 \mathrm{eV}\end{aligned}$ & 0 & - & - & - & - \\
\hline $\begin{aligned} E_{271}^{\prime}= & -13.915 \mathrm{eV} \\
& -13.92 \mathrm{eV}\end{aligned}$ & $\begin{array}{l}0.1033 \mathrm{eV} \\
0.103 \mathrm{eV}\end{array}$ & 0 & - & - & - \\
\hline $\begin{aligned} E_{272}^{\prime}= & -13.813 \mathrm{eV} \\
& -13.81 \mathrm{eV}\end{aligned}$ & $\begin{array}{l}0.2054 \mathrm{eV} \\
0.205 \mathrm{eV}\end{array}$ & $\begin{array}{l}0.1021 \mathrm{eV} \\
0.102 \mathrm{eV}\end{array}$ & 0 & - & - \\
\hline $\begin{aligned} E_{273}^{\prime}= & -13.712 \mathrm{eV} \\
& -13.71 \mathrm{eV}\end{aligned}$ & $\begin{array}{l}0.3064 \mathrm{eV} \\
0.306 \mathrm{eV}\end{array}$ & $\begin{array}{l}0.2031 \mathrm{eV} \\
0.203 \mathrm{eV}\end{array}$ & $\begin{array}{l}0.1010 \mathrm{eV} \\
0.101 \mathrm{eV}\end{array}$ & 0 & - \\
\hline $\begin{aligned} E_{274}^{\prime}= & -13.612 \mathrm{eV} \\
& -13.612 \mathrm{eV}\end{aligned}$ & $\begin{array}{l}0.4063 \mathrm{eV} \\
0.406 \mathrm{eV}\end{array}$ & $\begin{array}{l}0.3030 \mathrm{eV} \\
0.303 \mathrm{eV}\end{array}$ & $\begin{array}{l}0.2009 \mathrm{eV} \\
0.201 \mathrm{eV}\end{array}$ & $\begin{array}{l}0.0999 \mathrm{eV} \\
0.100 \mathrm{eV}\end{array}$ & 0 \\
\hline $\begin{aligned} E_{1}= & -13.605 \mathrm{eV} \\
& -13.605 \mathrm{eV}\end{aligned}$ & $\begin{array}{l}0.4134 \mathrm{eV} \\
0.413 \mathrm{eV}\end{array}$ & $\begin{array}{l}0.3102 \mathrm{eV} \\
0.3102 \mathrm{eV}\end{array}$ & $\begin{array}{l}0.2081 \mathrm{eV} \\
0.208 \mathrm{eV}\end{array}$ & $\begin{array}{l}0.1071 \mathrm{eV} \\
0.107 \mathrm{eV}\end{array}$ & $\begin{array}{l}0.00714 \mathrm{eV} \\
0.00714 \mathrm{eV}\end{array}$ \\
\hline$E_{275}^{\prime}=-13.513 \mathrm{eV}$ & $0.5051 \mathrm{eV}$ & $0.4019 \mathrm{eV}$ & $0.2997 \mathrm{eV}$ & $\begin{array}{l}0.1987 \mathrm{eV} \\
0190 \mathrm{eV}\end{array}$ & $0.0988 \mathrm{eV}$ \\
\hline $\begin{array}{c}-13.51 \mathrm{eV} \\
E_{276}^{\prime}=-13.416 \mathrm{eV}\end{array}$ & $\begin{array}{l}0.505 \mathrm{eV} \\
0.6029 \mathrm{eV}\end{array}$ & $\begin{array}{l}0.402 \mathrm{eV} \\
0.4996 \mathrm{eV}\end{array}$ & $\begin{array}{l}0.300 \mathrm{eV} \\
0.3975 \mathrm{eV}\end{array}$ & $\begin{array}{l}0.199 \mathrm{eV} \\
0.2965 \mathrm{eV}\end{array}$ & $\begin{array}{l}0.099 \mathrm{eV} \\
0.1966 \mathrm{eV}\end{array}$ \\
\hline$-13.42 \mathrm{eV}$ & $0.603 \mathrm{eV}$ & $0.500 \mathrm{eV}$ & $0.397 \mathrm{eV}$ & $0.296 \mathrm{eV}$ & $0.197 \mathrm{eV}$ \\
\hline$E_{277}^{\prime}=-13.319 \mathrm{eV}$ & $0.6995 \mathrm{eV}$ & $0.5963 \mathrm{eV}$ & $0.4942 \mathrm{eV}$ & $0.3932 \mathrm{eV}$ & $0.2932 \mathrm{eV}$ \\
\hline$-13.32 \mathrm{eV}$ & $0.700 \mathrm{eV}$ & $0.596 \mathrm{eV}$ & $0.494 \mathrm{eV}$ & $0.393 \mathrm{eV}$ & $0.293 \mathrm{eV}$ \\
\hline$E_{278}^{\prime}=-13.223 \mathrm{eV}$ & $0.7952 \mathrm{eV}$ & $0.6919 \mathrm{eV}$ & $0.5898 \mathrm{eV}$ & $0.4888 \mathrm{eV}$ & $0.3889 \mathrm{eV}$ \\
\hline$-13.22 \mathrm{eV}$ & $0.795 \mathrm{eV}$ & $0.692 \mathrm{eV}$ & $0.590 \mathrm{eV}$ & $0.489 \mathrm{eV}$ & $0.389 \mathrm{eV}$ \\
\hline$E_{279}^{\prime}=-13.129 \mathrm{eV}$ & $0.8898 \mathrm{eV}$ & $0.7865 \mathrm{eV}$ & $0.6844 \mathrm{eV}$ & $0.5834 \mathrm{eV}$ & $0.4835 \mathrm{eV}$ \\
\hline$-13.129 \mathrm{eV}$ & $0.890 \mathrm{eV}$ & $0.787 \mathrm{eV}$ & $0.684 \mathrm{eV}$ & $0.583 \mathrm{eV}$ & $0.484 \mathrm{eV}$ \\
\hline$E_{1}$ & $E_{275}^{\prime}$ & $E_{276}^{\prime}$ & $E_{277}^{\prime}$ & $E_{278}^{\prime}$ & $E_{279}^{\prime}$ \\
\hline 0 & - & - & - & - & - \\
\hline $\begin{aligned} E_{275,1}= & 0.0917 \mathrm{eV} \\
& 0.0917 \mathrm{eV}\end{aligned}$ & 0 & - & - & - & - \\
\hline $\begin{aligned} E_{276,1}= & 0.1894 \mathrm{eV} \\
& 0.189 \mathrm{eV}\end{aligned}$ & $\begin{array}{l}0.0977 \mathrm{eV} \\
0.098 \mathrm{eV}\end{array}$ & 0 & - & - & - \\
\hline $\begin{aligned} E_{277,1}= & 0.2861 \mathrm{eV} \\
& 0.286 \mathrm{eV}\end{aligned}$ & $\begin{array}{l}0.1944 \mathrm{eV} \\
0.194 \mathrm{eV}\end{array}$ & $\begin{array}{l}0.967 \mathrm{eV} \\
0.967 \mathrm{eV}\end{array}$ & 0 & - & - \\
\hline $\begin{aligned} E_{278,1}= & 0.3817 \mathrm{eV} \\
& 0.382 \mathrm{eV}\end{aligned}$ & $\begin{array}{l}0.2901 \mathrm{eV} \\
0.290 \mathrm{eV}\end{array}$ & $\begin{array}{l}0.1923 \mathrm{eV} \\
0.192 \mathrm{eV}\end{array}$ & $\begin{array}{l}0.956 \mathrm{eV} \\
0.956 \mathrm{eV}\end{array}$ & 0 & - \\
\hline $\begin{aligned} E_{279,1}= & 0.4764 \mathrm{eV} \\
& 0.476 \mathrm{eV}\end{aligned}$ & $\begin{array}{l}0.3847 \mathrm{eV} \\
0.385 \mathrm{eV}\end{array}$ & $\begin{array}{l}0.2870 \mathrm{eV} \\
0.287 \mathrm{eV}\end{array}$ & $\begin{array}{l}0.1903 \mathrm{eV} \\
0.190 \mathrm{eV}\end{array}$ & $\begin{array}{l}0.0946 \mathrm{eV} \\
0.0946 \mathrm{eV}\end{array}$ & 0 \\
\hline
\end{tabular}


Table 3. Transition energy confirmed in the energy range from $E_{544}^{\prime}$ to $E_{553}^{\prime}$. The measured values in this table almost match the theoretical values

\begin{tabular}{|c|c|c|c|c|c|}
\hline & $E_{544}^{\prime}$ & $E_{545}^{\prime}$ & $E_{546}^{\prime}$ & $E_{547}^{\prime}$ & $E_{548}^{\prime}$ \\
\hline $\begin{aligned} E_{544}^{\prime}= & -3.453 \mathrm{eV} \\
& -3.453 \mathrm{eV}\end{aligned}$ & 0 & - & - & - & - \\
\hline $\begin{aligned} E_{545}^{\prime}= & -3.441 \mathrm{eV} \\
& -3.441 \mathrm{e} \mathrm{V}\end{aligned}$ & $\begin{array}{l}0.0127 \mathrm{eV} \\
0.0127 \mathrm{eV}\end{array}$ & 0 & - & - & - \\
\hline $\begin{aligned} E_{546}^{\prime}= & -3.428 \mathrm{eV} \\
& -3.428 \mathrm{eV}\end{aligned}$ & $\begin{array}{l}0.0253 \mathrm{eV} \\
0.0253 \mathrm{eV}\end{array}$ & $\begin{array}{l}0.0126 \mathrm{eV} \\
0.0126 \mathrm{eV}\end{array}$ & 0 & - & - \\
\hline $\begin{aligned} E_{547}^{\prime}= & -3.416 \mathrm{eV} \\
& -3.416 \mathrm{eV}\end{aligned}$ & $\begin{array}{l}0.0378 \mathrm{eV} \\
0.0378 \mathrm{eV}\end{array}$ & $\begin{array}{l}0.0251 \mathrm{eV} \\
0.0251 \mathrm{eV}\end{array}$ & $\begin{array}{l}0.0125 \mathrm{eV} \\
0.0125 \mathrm{eV}\end{array}$ & 0 & - \\
\hline $\begin{aligned} E_{548}^{\prime}= & -3.403 \mathrm{eV} \\
& -3.403 \mathrm{eV}\end{aligned}$ & $\begin{array}{l}0.0502 \mathrm{eV} \\
0.050 \mathrm{eV}\end{array}$ & $\begin{array}{l}0.0376 \mathrm{eV} \\
0.0376 \mathrm{eV}\end{array}$ & $\begin{array}{l}0.0250 \mathrm{eV} \\
0.0250 \mathrm{eV}\end{array}$ & $\begin{array}{l}0.0125 \mathrm{eV} \\
0.0125 \mathrm{eV}\end{array}$ & 0 \\
\hline $\begin{aligned} E_{2}= & -3.401 \mathrm{eV} \\
& -3.401 \mathrm{eV}\end{aligned}$ & $\begin{array}{l}0.0521 \mathrm{eV} \\
0.0521 \mathrm{eV}\end{array}$ & $\begin{array}{l}0.0395 \mathrm{eV} \\
0.0395 \mathrm{eV}\end{array}$ & $\begin{array}{l}0.0269 \mathrm{eV} \\
0.0269 \mathrm{eV}\end{array}$ & $\begin{array}{l}0.0143 \mathrm{eV} \\
0.0143 \mathrm{eV}\end{array}$ & $\begin{array}{l}0.00189 \mathrm{eV} \\
0.00189 \mathrm{eV}\end{array}$ \\
\hline$E_{549}^{\prime}=-3.391 \mathrm{eV}$ & $0.0626 \mathrm{eV}$ & $0.0500 \mathrm{eV}$ & $0.0374 \mathrm{eV}$ & $0.0248 \mathrm{eV}$ & $0.0124 \mathrm{eV}$ \\
\hline$-3.391 \mathrm{eV}$ & $0.0626 \mathrm{eV}$ & $0.0500 \mathrm{eV}$ & $0.0374 \mathrm{eV}$ & $0.0248 \mathrm{eV}$ & $0.0124 \mathrm{eV}$ \\
\hline$E_{550}^{\prime}=-3.378 \mathrm{eV}$ & $0.0749 \mathrm{eV}$ & $0.0623 \mathrm{eV}$ & $0.0497 \mathrm{eV}$ & $0.0372 \mathrm{eV}$ & $0.0247 \mathrm{eV}$ \\
\hline$-3.378 \mathrm{eV}$ & $0.0749 \mathrm{eV}$ & $0.0623 \mathrm{eV}$ & $0.050 \mathrm{eV}$ & $0.0372 \mathrm{eV}$ & $0.0247 \mathrm{eV}$ \\
\hline$E_{551}^{\prime}=-3.366 \mathrm{eV}$ & $0.0872 \mathrm{eV}$ & $0.0745 \mathrm{eV}$ & $0.0619 \mathrm{eV}$ & $0.0494 \mathrm{eV}$ & $0.0370 \mathrm{eV}$ \\
\hline$-3.366 \mathrm{eV}$ & $0.087 \mathrm{eV}$ & $0.0745 \mathrm{eV}$ & $0.062 \mathrm{eV}$ & $0.0494 \mathrm{eV}$ & $0.037 \mathrm{eV}$ \\
\hline$E_{552}^{\prime}=-3.354 \mathrm{eV}$ & $0.0994 \mathrm{eV}$ & $0.0867 \mathrm{eV}$ & $0.0741 \mathrm{eV}$ & $0.0616 \mathrm{eV}$ & $0.0491 \mathrm{eV}$ \\
\hline$-3.354 \mathrm{eV}$ & $0.099 \mathrm{eV}$ & $0.0867 \mathrm{eV}$ & $0.074 \mathrm{eV}$ & $0.0616 \mathrm{eV}$ & $0.049 \mathrm{eV}$ \\
\hline$E_{553}^{\prime}=-3.342 \mathrm{eV}$ & $0.1115 \mathrm{eV}$ & $0.0988 \mathrm{eV}$ & $0.0862 \mathrm{eV}$ & $0.0737 \mathrm{eV}$ & $0.0613 \mathrm{eV}$ \\
\hline$-3.342 \mathrm{eV}$ & $0.111 \mathrm{eV}$ & $0.0990 \mathrm{eV}$ & $0.086 \mathrm{eV}$ & $0.074 \mathrm{eV}$ & $0.061 \mathrm{eV}$ \\
\hline$E_{2}$ & $E_{549}^{\prime}$ & $E_{550}^{\prime}$ & $E_{551}^{\prime}$ & $E_{552}^{\prime}$ & $E_{553}^{\prime}$ \\
\hline 0 & - & - & - & - & - \\
\hline $\begin{aligned} E_{549,2}= & 0.0105 \mathrm{eV} \\
& 0.0105 \mathrm{eV}\end{aligned}$ & 0 & - & - & - & - \\
\hline $\begin{aligned} E_{550,2}= & 0.0228 \mathrm{eV} \\
& 0.0228 \mathrm{eV}\end{aligned}$ & $\begin{array}{l}0.0123 \mathrm{eV} \\
0.0123 \mathrm{eV}\end{array}$ & 0 & - & - & - \\
\hline $\begin{aligned} E_{551,2}= & 0.0351 \mathrm{eV} \\
& 0.035 \mathrm{eV}\end{aligned}$ & $\begin{array}{l}0.0246 \mathrm{eV} \\
0.0246 \mathrm{eV}\end{array}$ & $\begin{array}{l}0.0123 \mathrm{eV} \\
0.0123 \mathrm{eV}\end{array}$ & 0 & - & - \\
\hline $\begin{aligned} E_{552,2}= & 0.0473 \mathrm{eV} \\
& 0.047 \mathrm{eV}\end{aligned}$ & $\begin{array}{l}0.0368 \mathrm{eV} \\
0.0368 \mathrm{eV}\end{array}$ & $\begin{array}{l}0.0244 \mathrm{eV} \\
0.0244 \mathrm{eV}\end{array}$ & $\begin{array}{l}0.0122 \mathrm{eV} \\
0.0122 \mathrm{eV}\end{array}$ & 0 & - \\
\hline $\begin{aligned} E_{553,2}= & 0.0594 \mathrm{eV} \\
& 0.059 \mathrm{eV}\end{aligned}$ & $\begin{array}{l}0.0489 \mathrm{eV} \\
0.049 \mathrm{eV}\end{array}$ & $\begin{array}{l}0.0366 \mathrm{eV} \\
0.0366 \mathrm{eV}\end{array}$ & $\begin{array}{l}0.0243 \mathrm{eV} \\
0.0243 \mathrm{eV}\end{array}$ & $\begin{array}{l}0.0121 \mathrm{eV} \\
0.0121 \mathrm{eV}\end{array}$ & 0 \\
\hline
\end{tabular}

\section{Conclusions}

1). It has been thought that Planck constant $h$ is a universal constant belonging to the same category as the speed of light in vacuum $c$ and the electric charge $e$.

Thus, it is valid to regard Planck constant not as a universal constant but as a micro material constants on par with the fine-structure constant $\alpha$ or the Rydberg constant $R_{\infty}$. 
2). This paper has pointed out the existence of a constant $\hbar_{\mathrm{s}}$. This constant is smaller than Planck constant, and is a physical quantity with dimensions of angular momentum. That is,

$$
\hbar_{\mathrm{s}}=\frac{1}{2} \frac{1}{4 \pi \varepsilon_{0}} \frac{e^{2}}{c} .
$$

In the micro world, there are two constants with the dimensions of angular momentum. What relates $\hbar$ and $\hbar_{\mathrm{s}}$ is the fine-structure constant $\alpha$.

$$
\alpha=\frac{2 \hbar_{\mathrm{S}}}{\hbar}=\frac{1}{4 \pi \varepsilon_{0}} \frac{e^{2}}{\hbar c} .
$$

This paper concludes that, just like $\hbar$ and $\alpha, \hbar_{\mathrm{s}}$ is a constant belonging to the micro material constants. The above two items are the main conclusions of this paper.

3). This paper has derived Equation (46) as a candidate for an unknown energy level in the hydrogen atom. However, Equation (15) can neatly explain the spectrum of the hydrogen atom, but a spectrum requiring Equation (46) has not been discovered. In addition, many data sets used to compare theoretical and experimental values include energies emitted from molecules other than hydrogen.

Thus there are also problems with Equation (46). However, this paper predicts that there is a high probability of an unknown energy level, which cannot be explained by quantum mechanics, existing in the hydrogen atom.

\section{Acknowledgements}

I would like to express my thanks to the staff at ACN Translation Services for their translation assistance.

\section{References}

Schiff, L. I. (1968). Quantum Mechanics (p. 472). New York: McGraw-Hill.

Suto, K. (2011). An energy-momentum relationship for a bound electron inside a hydrogen atom. Physics Essays, 24(2), 301-307. http://dx.doi.org/10.4006/1.3583810

Suto K. (2014). n=0 energy level present in the hydrogen atom. Applied Physics Research, 6(5), 109-115. http://dx.doi.org/10.5539/apr.v6n5p109

\section{Appendix}

In this paper, Equation (13) was obtained by starting from Equation (3). Equation (3) states that a hydrogen atom has an $n=0$ energy level. However, at present, no experimental evidence has been obtained to support the existence of such an energy level. Therefore, it will be confirmed here that Equation (13) can be derived without relying on Equation (3).

Referring to classical quantum theory, the total mechanical energy of the electron in a hydrogen atom has a negative value. The total mechanical energy of an electron is considered to be zero when the electron is separated from the atomic nucleus by a distance of infinity and remains at rest in that location. The total mechanical energy of Equation (15) is the value obtained from this perspective. However, even if we place an electron at rest an infinite distance from its nucleus, the relativistic energy of the electron is fundamentally not zero. According to Einstein, an electron in this state should have rest mass energy. According to quantum mechanics textbooks, the eigenvalue of the energy of a hydrogen atom as obtained from the Dirac equation, which is a relativistic wave equation, is as follows (Schiff, 1968).

$$
E=m_{\mathrm{e}} c^{2}\left[1-\frac{\gamma^{2}}{2 n^{2}}-\frac{\gamma^{4}}{2 n^{4}}\left(\frac{n}{|k|}-\frac{3}{4}\right)\right] .
$$

If we ignore for the third term of this equation and define it as an approximation, Equation (A1) can be written as follows.

$$
\begin{gathered}
E \approx m_{\mathrm{e}} c^{2}-\frac{1}{2}\left(\frac{1}{4 \pi \varepsilon_{0}}\right)^{2} \frac{m_{\mathrm{e}} e^{4}}{\hbar^{2}} \frac{1}{n^{2}} \\
=m_{\mathrm{e}} c^{2}+E_{n} .
\end{gathered}
$$

$E$ of Equation (A2.1) defines an absolute quantity, which includes the electron's rest mass energy. 
The energy of a hydrogen atom Equation (15) corresponds to the reduction in the electron's rest mass energy, while conversely, Equation (A2.2) corresponds to the electron's remaining rest mass energy.

Even if the electron which was at rest begins moving in free space, and even if it is absorbed into an atom, the starting point of the electron's energy for either case is its rest mass energy. From this fact, the relativistic energy in absolute terms, $E_{\mathrm{re}, n}$, for a hydrogen atom is defined as below:

$$
E_{\mathrm{re}, n}=m_{\mathrm{e}} c^{2}+E_{n} \cdot(\mathrm{A} 3)
$$

This shows that the following inequalities hold for the relativistic energy and total mechanical energy of the electron in the hydrogen atom.

$$
\begin{aligned}
& 0 \leq E_{\mathrm{re}, n}<m_{\mathrm{e}} c^{2} . \\
& -m_{\mathrm{e}} c^{2} \leq E_{n}<0 .
\end{aligned}
$$

This does not mean that the existence of an $n=0$ energy level has been proven. However, logically speaking, the lower limit of the energy level of the hydrogen atom becomes $E_{n}=-m_{\mathrm{e}} c^{2}$ (i.e., $\left.E_{\mathrm{re}}=0\right)$.

Therefore, Equation (22) can be written as follows:

$$
-m_{\mathrm{e}} c^{2}=-\frac{1}{2} \frac{1}{4 \pi \varepsilon_{0}} \frac{e^{2}}{r} .
$$

Solving this, the following $r$ is obtained.

$$
r=\frac{1}{2} \frac{1}{4 \pi \varepsilon_{0}} \frac{e^{2}}{m_{\mathrm{e}} c^{2}}=\frac{r_{\mathrm{e}}}{2} .
$$

For the $p$ corresponding to this $r$, the following value is obtained by setting $E_{\mathrm{re}, n}=0$ in Equation (3).

$$
p=m_{\mathrm{e}} c \text {. }
$$

This confirms that the existence of $E_{0}$ is not essential to inferring the value of $\hbar_{\mathrm{s}}$, which is a candidate for the minimum unit of physical quantities having a dimension of angular momentum.

\section{Copyrights}

Copyright for this article is retained by the author(s), with first publication rights granted to the journal.

This is an open-access article distributed under the terms and conditions of the Creative Commons Attribution license (http://creativecommons.org/licenses/by/3.0/). 